\section{FedUni ResearchOnline \\ https://researchonline.federation.edu.au}

Copyright Notice

This is the peer-reviewed version of the following article:

Chundhoo, V., Chattopadhyay, G., Gunawan, I., Ibrahim, Y. (2017) OEE improvement of thermoforming machines through application of TPM at Tibaldi Australasia. 2017 IEEE International Conference on Industrial Engineering and Engineering Management, IEEM 2017; Singapore, Singapore; 10th-13th December 2017 p. 929-933.

Which has been published in final form at:

https://doi.org/10.1109/IEEM.2017.8290028

Copyright (C) 2017 IEEE. Personal use of this material is permitted. Permission from IEEE must be obtained for all other uses, in any current or future media, including reprinting/republishing this material for advertising or promotional purposes, creating new collective works, for resale or redistribution to servers or lists, or reuse of any copyrighted component of this work in other works. 


\title{
OEE improvement of thermoforming machines through application of TPM at Tibaldi Australasia
}

\author{
V. Chundhoo ${ }^{\text {a }}$, G. Chattopadhyay ${ }^{\text {b }}$, . Gunawan $^{\mathrm{c}}$ and M. Yousef Ibrahim ${ }^{\mathrm{d}}$ \\ ${ }^{\mathrm{a}, \mathrm{b}, \mathrm{d}}$ School of Engineering and Information Technology, Faculty of Science and Technology, Federation \\ University, Northways Road, Churchill, PO Box 3191, Gippsland Mail Centre, Vic 3841 \\ ${ }^{c}$ Entrepreneurship, Commercialisation and Innovation Centre, The University of Adelaide, SA 5005
}

\begin{abstract}
Overall Equipment Effectiveness (OEE) evaluates quantitatively how effectively a manufacturing operation is utilised. Total Productive Maintenance (TPM) was considered by Tibaldi, a leading food manufacturer in Australia for achieving OEE. This research project has identified performance gaps, developed plan and implemented it in Thermoforming area of the business. The developed methodology helped Tibaldi in improving productivity and quality through TPM involving machines, equipment, processes, and employees. This paper demonstrates how this can be achieved by reducing lead time and establishing lean environment. Productivity improvement through the devised methodology led to further enhancement of competitiveness of the organisation for domestic and international markets of processed food manufactured by Tibaldi Australia. Lessons learned from application of TPM in Thermoforming, a key asset area, is rolled out to other sections of the plat and results from this pilot study are presented in this paper.
\end{abstract}

\section{INTRODUCTION}

Overall Equipment Effectiveness (OEE) evaluates how effectively a manufacturing operation is utilized and is expressed in terms of Performance, Availability and Quality. Performance is measured in terms of whether plant is operated as per expected speed, reduced speed or with minor stops. Availability is influenced by breakdowns and product changeover. Quality is determined in terms of acceptance and rejects in startup, during production runs and customer returns. Maintenance performance and its measure is an important part of reducing losses and productivity improvement [1]. Reliability improvement has been used in various organisations including design and configuration changes and maintenance intervals [2, 3]. The objective of this project at Tibaldi was to identify, prioritize and eliminate the causes of the losses in the production.

Total Productive Maintenance (TPM) technique has been used by various organisations for business performance. Significant research has been conducted for various sectors and used for improving equipment effectiveness, eliminating breakdowns, reducing costs and promoting autonomous maintenance $[4,5,6,7]$. It focuses on proactive and preventive techniques for improving equipment reliability. Areas considered are: focused Improvement, autonomous maintenance, planned maintenance, quality maintenance, cost deployment, early equipment management, training and education and Safety Health Environment

Tibaldi [8] has a large portfolio of food products for domestic and international customers. This includes fresh sausages, ham and bacon to specialised air-dried salamis and cooked frankfurts for Coles, Woolworths, Aldi, Costco, FoodWorks, Independent Delicatessens and many other businesses. This project was aimed to further develop export markets with a focus on the ASIAN and Pacific Island countries. Tibaldi needed to produce and supply highest quality of products at competitive prices and comply with regulatory requirements and customer specifications. High quality comes with minimum variability of products and high performance level of key assets. Thermoforming is a key asset of the business to process plastic bowls, deli containers, meat trays, and a variety of other packaging products. It was taken as a pilot study. TPM helped in significant performance enhancement and reduction of risk to the business. It covered identifying gaps, cost effective solution for improving overall equipment effectiveness of five thermoforming machines. It improved skills and performance of processes, reduced change over time and risks of production loss and product quality.

\section{METHODOLOGY}

Total Productive Maintenance needs to consider how to maximize equipment effectiveness throughout its entire life using robust processes, safety culture, long term view and participation and motivation of the entire work force [9]. Body of knowledge shows TPM implementation reduces unexpected machine breakdowns for improving OEE[10, 11,12,13]. Tibaldi's TPM implementation methodology was tailored to suit its own requirements and global competition in processed food market.

Analysis of performance led to a decision for implementation of TPM. Unavailability is considered as a measure of KPI in Tibaldi Australia. Quality or line performance and OEE were not analysed in details. Initial analysis showed thermoforming and packaging processes are major 
contributors to those issues. OEE of thermoforming packaging production lines were analysed in detail. Losses identified in detailed analysis are: shut down (planned) maintenance, production adjustments, equipment failures, process failures, normal production losses, abnormal production losses, quality defects, and reprocessing time.

Table 1.0 shows how OEE values based on historical production data of last 6 months before TPM initiative.

\section{TABLE 1.0 RESULT FROM 6 MONTHS OEE TRACKING} BEFORE TPM

\begin{tabular}{|c|cccc|c|}
\cline { 2 - 5 } \multicolumn{1}{c|}{} & \multicolumn{4}{c|}{ Percentage } & \multicolumn{1}{c}{} \\
\hline Line & Breakdown & Availability & Performance & Quality & OEE \\
\hline R240 & 18.5 & 81.5 & 80.1 & 91.0 & 0.59 \\
R530B & 17.3 & 82.7 & 88.0 & 93.0 & 0.68 \\
R230A & 16.4 & 83.6 & 87.3 & 91.0 & 0.66 \\
R535 & 15.7 & 84.3 & 82.7 & 91.0 & 0.63 \\
R145 & 14.3 & 85.7 & 80.5 & 90.0 & 0.62 \\
\hline
\end{tabular}

Analysis shows that reactive maintenance is below $20 \%$, which is considered a candidate for the implementation of TPM. Tibaldi Australasia did not have detailed Asset Management Plan. An asset management plan was drafted and rolled out for further enhancing quality in maintenance decisions. Production data for thermoformer was analysed for specific issues and findings as presented in Table 2.0:

Operator errors

- Downtime due to equipment not maintained properly

- Non-value-added activities such as product change overs

TABLE 2.0 ANALYSIS OF SPECIFIC LINE ISSUES

\begin{tabular}{|l|l|}
\hline Stoppage Type & $\begin{array}{l}\text { \% of All Stoppages (24 } \\
\text { Weks of data) }\end{array}$ \\
\hline Operators/Human & 17 \\
\hline Breakdown & 18 \\
\hline Change Overs & 25 \\
\hline
\end{tabular}

Corporate knowledge was collated through meetings and brainstorming sessions to arrive at consensus on how to prevent those problems in the future and provided in Table3.0.

TABLE 3.0 HOW TO ADDRESS SPECIFIC LINE ISSUES

\begin{tabular}{|l|l|}
\hline Stoppage Type & How to prevent \\
\hline Operators/Human & Training/TPM \\
\hline Breakdown & $\begin{array}{l}\text { Asset } \\
\text { management/RCM/TPM }\end{array}$ \\
\hline Change Overs & TPM/SMED \\
\hline
\end{tabular}

Further analysis of down time at subsystem level is carried out in detail as shown in Fig.1.

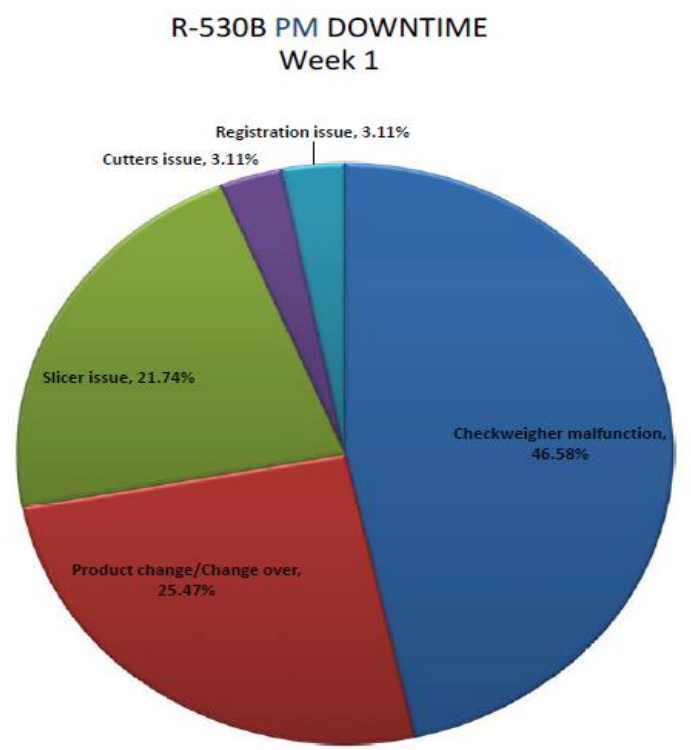

Fig. 1. Downtime analysis.

TPM implementation is detailed from Stages provided below.

\section{RESULTS}

Stage 1. Evaluating effectiveness of the current maintenance program.

Tibaldi's Preventive Maintenance program consisted 6-monthly time based Original Equipment Manufacturer (OEM) service contract backed up by an internal minor adjustments and lubrication program. After analyzing 35 weeks of historical production data, reactive maintenance percentage was observed to be $20 \%$. Wireman [14] states that for TPM to be effective, reactive maintenance must be less than $20 \%$. No immediate changes were made to current maintenance strategy. Availability was used as a Key Performance Indicator (KPI). Changes were made to data collection on the production lines and Overall Equipment Effectiveness (OEE) was introduced as a function of availability (ã), utilization (U) and quality (Q) using production data.

$$
O E E=\tilde{\mathrm{a}} \times \mathrm{U} \times \mathrm{Q}
$$

\section{Stage 2. Reviewing maintenance stores}

To improve service level of stores, parts were identified, organized and tagged. Service level is measured as percentage of time that a part is in stock when requested. Reliability Centred Maintenance (RCM) was undertaken to better understand the maintenance requirements and criticality of spares for all the Thermoformers. RCM was further addressed in Stage7. Spares re-order level was increased by $25 \%$ for critical items. Insurance spares (where the consequences of not having the item are high) were also identified. A new stock level was set based on criticality for 
preventing overstocking. This resulted improved service level to $95 \%$.

\section{Stage 3. Reviewing work order System}

Work order system at Tibaldi consisted of a paper based system. Elements were: maintenance work order (MWO), maintenance job order (MJO), verbal order (VO) and capital work order (CWO). Tibaldi's Manual Maintenance Management System (MMMS) was required to be replaced mainly due to its inability to efficiently facilitate planning and scheduling of work orders. Historically, $70 \%$ of work orders were hindered by waiting periods such as: further approvals, work permits, production windows. Report generation, cost and performance tracking were tedious and time consuming. Safefood360, a computerised maintenance management system (CMMS) was introduced to run in parallel with the MMMS. Finally, MMMS was phased out during this project.

\section{Stage 4. A review of planning and scheduling}

At Tibaldi, the maintenance strategy is influenced by the production strategy. Maintenance planning and scheduling would still be in consultation with production planning. However, following logical sequences were introduced in a documented process: Identify work, Investigate, Get advice from maintenance and production supervisor, Determine standards and apply, Confirm job scope, Make job plan and set up work orders on CMMS, Determine resources, Establish manpower by craft, Estimate cost, set priority and get approval, Estimate preliminary time to do job, Open work orders and order materials, Await receipts of materials, Check production window/s, Arrange appropriate access solutions and tools if required, Conduct scheduling meeting, Monitor job execution and note cost and performance and Record on CMMS. Results: After the implementation of the CMMS, $80 \%$ of all maintenance activities were in planned mode

\section{Stage 5. Computerised Maintenance Management System}

Safefood360 is now used as Tibaldi's food safety, quality and compliance management system in one platform. As a cost effective solution, it was implemented also as a CMMS resulting in reduction of paperwork, improvement in record keeping, better management of the spare part inventory and facilitated better scheduling and work planning including report generation.

\section{Stage 6. Operator involvement}

Kaizen (continuous improvement) was introduced as a team based approach consisting of production supervisors, engineering and production planners to identify bottlenecks and improve processes across all the Thermoformers. Three manual processes (loading, operations and change overs) within the thermoforming processes were identified as bottlenecks. Barriers of implementation were identified and resolved [15].Value stream mapping was used to reduce the manufacturing lead time, improve information flow and production quality.

Takt time was introduced for analysing the production performance.

$$
\text { Takt time }=\left(\frac{\text { Effective working time per shift })}{\text { Customer Requirement per shift })}\right)
$$

Effective working time per shift $=450 \mathrm{~min}$

6 packs are discharged every cycle at an achievable cycle rate of $7.0 \mathrm{cycles} / \mathrm{min}$ at normal operating conditions.

Customer Requirement per shift $=(7.0$ cycles $/ \mathrm{min} X$ 6 $)$ $=(42 \times 450)=18900$ packs

Hence: Takt $=1.429 \mathrm{sec}$

The higher Takt time means lower productivity resulting higher manufacturing costs. From the current state value stream mapping, a total lead time of $1.21 \times 60=67.26 \mathrm{sec}$ was noted. $67.26 \mathrm{sec}$ correspond to a cycle speed of 6.24 cycles/min. Therefore, a Takt Time of $1.602 \mathrm{sec}$. An increased time of $(1.602-1.429)=0.173 \mathrm{sec}$ for each pack Therefore, to meet a demand of 18900 packs, Tibaldi needed to run 0.9 hours' overtime per shift at a cost of $\$ 200$ 000 per year.

Time and motion study were conducted to understand the current times for loading, trim removals and operation. Training and standard loading procedures were reenforced. Table 4.0 shows standard set by Tibaldi.

TABLE 4.0 RESULT FROM TIME AND MOTION STUDY

\begin{tabular}{|c|c|c|}
\hline Manual Action & Average Time/Seconds & Standard \\
\hline Start/Stop/Reset & $5 \mathrm{Sec}$ & $4 \mathrm{Sec}$ \\
\hline Trim Removal & $20 \mathrm{Secs}$ & $15 \mathrm{Sec}$ \\
\hline Loading & $15 \mathrm{Secs}$ & $10 \mathrm{Sec}$ \\
\hline
\end{tabular}

It was noted that change overs were difficult to be incorporated in the value stream maps and was regarded as a non-value added activity. Reducing change-over downtime without compromising the work quality was a key factor in this study. Single Minute Exchange of Die (SMED) technique was applied in four stages to reduce change over time. Following steps were taken systematically:

1. Analyse Internal and External Setups in Preliminary Stage.

2. Separate Internal and External Setup

3. Convert Internal Setup to External Setup

4. Streamline both Internal and External setup 
The average change over time for R530A on a 6 die format was 58 mins. Single Minute Exchange of Die (SMED) means all changeovers and startups should take less than 10 minutes (in other words, "single-digit minute"). The changeover time of Thermoformer R530A on a 6-format change-over to $3085 \mathrm{secs}(51 \mathrm{~min})$ and further streamlining reduced this to $42 \mathrm{~min}$. A total reduction of 16 mins of non-value added activities across the changeover processes was achieved.

\section{Stage 7. Predictive Maintenance and Reliability Engineering}

Reliability Centered Maintenance was applied to all Thermoformers. An assessment on criticality was conducted based on criticality matrix [16]. A qualitative approach was adopted and criticality value 3 and beyond were not subjected to RCM. RCM worksheets were prepared and utilised for informed decision making [17, 18]. Sealing gaskets, valve seats and O-rings which are subjected to direct contact with the product, environment, gas and cooling water were proposed to be replaced on a 6monthly basis as specified in OEM manual. Other items such as sealing dies, forming plates were recommended to be monitored for deterioration. A basic condition monitoring was implemented at a cost of $\$ 15 \mathrm{~K}$ (equipment and training only). Maintenance plan was reviewed for enhanced operator involvement as per TPM masterplan and is backed by existing 6 monthly OEM service to prevent unexpected asset deterioration.

\section{Stage 8. Optimum Replacement Time}

Historical performance including data and Repair and Maintenance spending analysis revealed a need to study a method to find optimum replacement time for one of the Thermoformers coded as R240. The criteria for the replacement timings were based on the following 3 factors: retaining R240 too long would increase total cost due to increased maintenance cost and downtime, Capacity needs had changed due to technological development and Disposing R240 too quickly increases the total cost due to an increase in capital expenditure.

The risk management process for Thermoformers covered Recognition, Evaluation and Control. Financial consequences were further analyzed using a qualitative assessment along with executive judgement in addition to quantitative risk analysis. Tibaldi's occupational and health safety policy states that $\mathrm{OH} \& \mathrm{~S}$ is an integral part of its business performance and it is committed to achieving a high level of health and safety performance with compliance to regulatory requirements. OH\&S policy is communicated, practiced across all levels in the organisation, reviewed and maintained at regular intervals as specified in the policy. Its main aim is to promote and try to achieve zero harm and zero near miss incidents.
Mean Annual Cost Equivalent (MACE) was used and least value was chosen for the year in replacement decision. In this case it is year 9 from analysis as shown in Table 5.0.

\section{TABLE 5.0 COST ANALYSIS FOR THERMOFORMER}

\begin{tabular}{|c|c|c|c|c|c|}
\hline $\begin{array}{c}\text { Discountd } \\
\text { Total } \\
\text { Yearly } \\
\text { Costs } \mathbf{\$} \text { ) }\end{array}$ & $\begin{array}{c}\text { Cumulativ } \\
\mathbf{e} \\
\text { Discounted } \\
\text { Cost } \mathbf{( \$ )}\end{array}$ & $\begin{array}{c}\text { Total } \\
\text { discounted } \\
\text { cost } \mathbf{( \$ )}\end{array}$ & $\begin{array}{c}\text { Annual } \\
\text { Equivalenc } \\
\text { y Factor }\end{array}$ & $\begin{array}{c}\text { MACE } \\
\mathbf{( \$ )}\end{array}$ & $\begin{array}{c}\text { Repla } \\
\text { cemnt } \\
\text { Period }\end{array}$ \\
\hline$\$ 17,858$ & $\$ 17,858$ & $\$ 116,053$ & 1.12 & $\$ 129,979$ & 1 \\
$\$ 17,538$ & $\$ 35,396$ & $\$ 212,530$ & 0.5917 & $\$ 125,754$ & 2 \\
$\$ 21,354$ & $\$ 56,750$ & $\$ 297,299$ & 0.4163 & $\$ 123,766$ & 3 \\
$\$ 20,336$ & $\$ 77,086$ & $\$ 354,661$ & 0.3292 & $\$ 116,755$ & 4 \\
$\$ 19,859$ & $\$ 96,945$ & $\$ 415,377$ & 0.2774 & $\$ 115,226$ & 5 \\
$\$ 15,198$ & $\$ 112,143$ & $\$ 462,696$ & 0.2434 & $\$ 112,620$ & 6 \\
$\$ 20,354$ & $\$ 132,497$ & $\$ 514,899$ & 0.2191 & $\$ 112,814$ & 7 \\
$\$ 18,983$ & $\$ 151,480$ & $\$ 548,486$ & 0.2013 & $\$ 110,410$ & 8 \\
$\$ 18,030$ & $\$ 169,510$ & $\$ 582,966$ & 0.1877 & $\$ 109,423$ & 9 \\
$\$ 16,744$ & $\$ 186,254$ & $\$ 625,074$ & 0.177 & $\$ 110,638$ & 10 \\
$\$ 15,238$ & $\$ 201,492$ & $\$ 652,617$ & 0.1684 & $\$ 109,901$ & 11 \\
$\$ 13,862$ & $\$ 215,354$ & $\$ 680,699$ & 0.1614 & $\$ 109,865$ & 12 \\
\hline
\end{tabular}

Analysis of OEE for March - Nov, 2016 shows an improvement across all Thermoforms and is shown in Fig2.0.

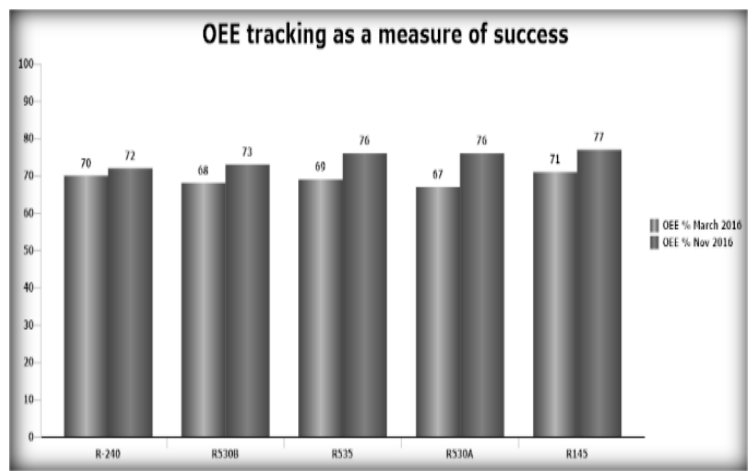

Fig. 2. OEE Tracking after implementation of TPM.

\section{CONCLUSION}

TPM implemented in Tibaldi Australasia in 2016, resulted in improvement in Overall Equipment Effectiveness (OEE). Reactive maintenance was reduced to less than 20\%. Maintenance stores achieved 95\% service level. The CMMS (Safefood360) improved work order system, maintenance work planning and scheduling. Value Stream Maps were introduced to better understand process effectiveness, information flow and bottlenecks within the thermoforming process lines. Kaizen events were used as a team based approach to reduce ineffective manual processes. Single Minute Exchange of Die (SMED) was applied to drastically reduce change over 
times and elimination/ reduction of non-value added activities. Takt time was calculated based on current and future value maps. Set target time for reduced manufacturing lead time resulting in improved productivity within the thermoforming lines Mean Annual Cost Equivalent (MACE) method was introduced to find optimum replacement intervals. Overall Equipment Effectiveness (OEE) trending was introduced as KPI. Capital planning and budget process was revised using Reliability Centered Maintenance (RCM). Risk management processes were revised focusing recognition, evaluation and control of hazards. The next stage of this project is to continually promote TPM across all levels within Tibaldi and apply to all critical assets and change the maintenance culture for achieving TPM maturity. With the implementation of and continued support for TPM after this pilot run, downtime has significantly com down. Nonvalue added activities such as unnecessary handling and extra change over time has been reduced significantly through Kaizen and SMED. The effectiveness of thermoforming processes are being monitored for one year. Further improvement of Takt time might be possible when TPM achieves maturity over a period of time. Performance rate is now being tracked continually on weekly basis. Low performance rate of Thermoformers are being tagged as part of TPM implementation. Rejects and reworks rate are now continually analyzed and root causes are being investigated though rigorous RCA sessions. In addition, following rules were introduced: Establish baseline level of conditions, Comply with condition of use, Restore loss in performance/deterioration, Correct Design Weaknesses, Improve Skills for operations and maintenance and Eliminate/ control accelerated deteriorations.

\section{ACKNOWLEDGMENT}

Authors wish to thank Mr. Peter Giddy CEO of Tibaldi Australasia for sponsoring this project and providing necessary resources for implementing this and allow as part of Post Graduate Studies in Maintenance and Reliability Engineering under Federation University Australia.

\section{REFERENCES}

[1] Parida, A \& Chattopadhyay, G , 'Development of a Multi criteria Hierarchical Maintenance Performance Measurement (MPM) model', Journal of Quality in Maintenance Engineering, Vol 13, Issue 3, 241-258, 2007.

[2] Kumar, S, Chattopadhyay, G \& Kumar, U (eds), 'Reliability Improvement through Alternative Design and Maintenance Decision - A Case Study',
Reliability Engineering and System Safety, Vol 92 Issue 7, 983-991, 2007.

[3] Chattopadhyay, G, Reddy, V \& Larsson, P. O, 'Decision on Economical Rail Grinding Interval for Controlling Rolling Contact Fatigue (RCF)', International Transactions in Operational Research, Vol 12, Issue 6, 545-558, 2005.

[4] Chattopadhyay G and Yun, WY, 'Modelling and Analysis of Warranty Cost for 2D-Policies Associated with Sale of Second-Hand Products', International Journal of Reliability and Applications, Vol 7, Issue 1, 71-77, 2006.

[5] Ahuja, I.P.S. and Khamba, J.S., "Total productive maintenance: literature review and directions", International Journal of Quality \& Reliability Management, Vol. 25 Iss 7 pp. 709 - 756, 2008.

[6] Ahuja, I.P.S., Singh, T.P., Sushil, M. and Wadood, A., "Total productive maintenance implementation at Tata Steel for achieving core competitiveness", Productivity, Vol. 45 No. 3, pp. 422-428, 2004.

[7] Bhadury, B., "Management of productivity through TPM”, Productivity, Vol. 41 No. 2, pp. 240-51.200.

[8] Tibaldi: http://www.tibaldi.com.au/export/

[9] Nakajima, S., Introduction to Total Productive Maintenance (TPM), Productivity Press, Portland, OR, 1988.

[10]Gosavi, A., "A risk-sensitive approach to total productive maintenance", Automatica, Vol. 42 No. 8, pp. 1321-1330, 2006.

[11] McKone, K.E., Roger, G.S. and Cua, K.O., "The impact of total productive maintenance practices on manufacturing performance", Journal of Operations Management, Vol. 19 No. 1, pp. 39-58, 2001.

[12] Singh, R., Gohil, A. M., Shah, D. B., Desai, S., Total Productive Maintenance (TPM) Implementation in a Machine, Procedia Engineering 51, 592 - 599, 2013.

[13] Chan, F. T. S. , Lau, H. C. W., Ip, R. W. L, Chan, H. K. \& Kong, S., "Implementation of total productive maintenance: A case study", Int. J. Production Economics, Vol. 95, p. 71-94, 2005.

[14] Wireman, T., Total Productive Maintenance, Industrial Press Inc., New York, NY, 2004.

[15] Attri, R., Grover, S., Dev, N. and Kumar, D.,, Analysis of barriers of total productive maintenance (TPM), International Journal of System Assurance Engineering and Management 4, 365-377, 2013.

[16] Standard Australia (2011). Australian Standard AS 60300. Dependability Management - Application guide - Reliability centred maintenance AS 60300 2011.

[17] Moubray, J., Reliability Centered Maintenance, 2nd ed., Industrial Press, New York, NY, 1997.

[18] Ben-Daya, M., "You may need RCM to enhance TPM implementation", Journal of Quality in Maintenance Engineering, Vol. 6 No. 2, pp. 82-87, 2000. 